This will be recognised as a landmark study, as it is the first to demonstrate a clear improvement in LCI in response to a recognised CF treatment in a population with normal spirometry results. The study is well designed and, in addition, the mass spectrometer-based sulfur hexafluoride $\left(\mathrm{SF}_{6}\right) \mathrm{MBW}$ hardware and software is identical to that employed in numerous previous studies, and consistent with recent taskforce recommendations for this technique. ${ }^{5}$ The researchers could be criticised for not employing a control group, and also for not paying sufficient attention to the baseline variability of their outcome measures when interpreting the effect of their intervention; however, both are minor criticisms.

There are still challenges ahead for researchers intending to utilise LCI as an outcome measure in early CF. Long-term prospective longitudinal studies tracking LCI from infancy into adulthood are required, but data collection for such studies is inevitably lengthy and complex. Ultimately it will be necessary to demonstrate that children with CF managed with regular LCI monitoring have better outcomes than peers monitored by more conventional methods. In parallel, clinicians will expect that manufacturers develop MBW systems that are cheaper and more robust than the current home-built systems, and validated to the same standards. This author is not aware of any commercially available system that currently meets these standards, but it is possible to report two developments. One is a system built around a modified photoacoustic gas analyser and employed by the UK gene therapy consortium. ${ }^{13}$ The second is a modified ultrasonic flowmeter system developed by a German group, and currently employed in a German multicentre trial, ${ }^{20} 21$ Both have been validated against the mass spectrometer system developed by Gustafsson et $a l^{12}$ and show great promise, at least for LCI measurement in preschool children and above. At present the researchers' modifications have not been commercialised by the manufacturers, but there is potential for the future.

\section{Competing interests None.}

Provenance and peer review Commissioned; not externally peer reviewed.

Thorax 2010;65:373-374

doi:10.1136/thx.2009.132100

\section{REFERENCES}

1. Quanjer PH, Stocks J, Polgar G, et al. Compilation of reference values for lung function measurements in children. Eur Respir J 1989;2(Suppl 4):184s-261s.

2. Dodge JA, Lewis PA, Stanton M, et al. Cystic fibrosis mortality and survival in the UK: 1947-2003. Eur Respir J 2007;29:522-6.

3. Davis SD, Brody AS, Emond MJ, et al. Endpoints for clinical trials in young children with cystic fibrosis. Proc Am Thorac Soc 2007:4:418-30.

4. Hulskamp G, Pillow JJ, Stocks J. Lung function testing in acute neonatal respiratory disorders and chronic lung disease of infancy: a review series. Pediatr Pulmonol 2005;40:467-70.

5. Beydon N, Davis SD, Lombardi E, et al. An official American Thoracic Society/European Respiratory Society statement: pulmonary function testing in preschool children. Am J Respir Crit Care Med 2007:175:1304-45.

6. Dawson SV, Elliot EA. Wave speed limitation on expiratory flow-a unifying concept. J App/ Physiol 1977;43:498-515

7. Macklem PT, Mead J. Resistance of central and peripheral airways measured by a retrograde catheter. J Appl Physiol 1967;22:395-401.

8. Davis SD, Fordham LA, Brody AS, et al. Computed tomography reflects lower airway inflammation and tracks changes in early cystic fibrosis. Am J Respir Crit Care Med 2007;175:943-50.
9. Brody AS, Kosorok MR, Li Z, et al. Reproducibility of a scoring system for computed tomography scanning in cystic fibrosis. J Thorac Imaging 2006;21:14-21.

10. Smith-Bindman R, Lipson J, Marcus R, et al. Radiation dose associated with common computed tomography examinations and the associated lifetime attributable risk of cancer. Arch Intern Med 2009:169:2078-86.

11. Aurora P, Bush A, Gustafsson P, et al. Multiplebreath washout as a marker of lung disease in preschool children with cystic fibrosis. Am J Respir Crit Care Med 2005;171:249-56

12. Gustafsson PM, Aurora P, Lindblad A. Evaluation of ventilation maldistribution as an early indicator of lung disease in children with cystic fibrosis. Eur Respir $J$ 2003;22:972-9

13. Horsley AR, Gustafsson PM, Macleod KA, et al. Lung clearance index is a sensitive, repeatable and practical measure of airways disease in adults with cystic fibrosis. Thorax 2008;63:135-40.

14. Gustafsson PM, De Jong PA, Tiddens HA, et al. Multiple-breath inert gas washout and spirometry versus structural lung disease in cystic fibrosis. Thorax 2008:63:129-34

15. Owens C, Aurora P, Oliver $\mathrm{C}$, et al. Ventilation inhomogeneity, gas trapping and high resolution CT findings in young children with cystic fibrosis [abstract]. Am J Resp Crit Care Med 2008;177:A773.

16. Kraemer R, Blum A, Schibler A, et al. Ventilation inhomogeneities in relation to standard lung function in patients with cystic fibrosis. Am J Respir Crit Care Med 2005;171:371-8.

17. Robinson PD, Cooper P, Van Asperen P, et al. Using index of ventilation to assess response to treatment for acute pulmonary exacerbation in children with cystic fibrosis. Pediatr Pulmonol 2009;44:733-42.

18. Scrase E, Oliver C, Kozlowska W, et al. Change in lung clearance index (LCl) following intravenous antibiotic intervention in children with CF [abstract]. Eur Respir J 2008;32:514s-15s.

19. Amin R, Subbarao P, Jabar A, et al. Hypertonic saline improves the $\mathrm{LCl}$ in paediatric patients with $\mathrm{CF}$ with normal lung function. Thorax 2010;65:379-83.

20. Fuchs SI, Buess C, Lum S, et al. Multiple breath washout with a sidestream ultrasonic flow sensor and mass spectrometry: a comparative study. Pediatr Pulmonol 2006;41:1218-25.

21. Fuchs SI, Sturz J, Junge S, et al. A novel sidestream ultrasonic flow sensor for multiple breath washout in children. Pediatr Pulmonol 2008;43:731-8.

\title{
Effects of steroid therapy on inflammatory cell subtypes in asthma
}

\section{Louis-Philippe Boulet}

Asthma is a chronic condition that usually develops after environmental exposures in

Correspondence to Louis-Philippe Boulet, Institut universitaire de cardiologie et de pneumologie de Québec, 2725 chemin Sainte-Foy, Québec, G1V 4G5, Canada; Ipboulet@med.ulaval.ca genetically predisposed individuals. ${ }^{1}$ It is considered an inflammatory disease leading to airway structural changes (remodelling), both of these processes being involved in the development of airway hyper-responsiveness (AHR) and variable airway obstruction. $^{2}$ When inflammation and remodelling increase to a sufficient degree, symptomatic asthma occurs. ${ }^{3}$

Although asthma has been recognised for a very long time as a heterogeneous condition, recent efforts have been devoted to better characterising its various phenotypes. ${ }^{4}$ The term 'phenotype' refers to 'a set of observable characteristics of an individual or group resulting from the interaction of its genotype with its environment'. Although these phenotypes may overlap or possibly vary over time, their characterisation may help to identify the predominant mechanisms involved and specific patterns of clinical presentation, predict clinical outcomes and may guide treatment. There is still, however, a lack of data in this field. 
Various classification systems have been proposed for asthma phenotypes. ${ }^{4}$ Currently, these phenotypes are usually defined according to their inducers, physiological characteristics, clinical features or-particularly since the development of non-invasive measures of airway inflammation-by their inflammatory characteristics. ${ }^{5-7}$ The main categories of airway inflammatory phenotypes identified in subjects with asthma are the eosinophilic and non-eosinophilic types, with the latter including neutrophilic and paucigranulocytopenic subtypes. A mixed form also exists in which both eosinophils and neutrophils are increased. These inflammatory phenotypes can be observed in children as well as in adults. ${ }^{8} 9$

A frequently encountered phenotype of asthma is the eosinophilic type. It is associated with allergic or occupational asthma, steroid withdrawal, aspirin intolerance/nasal polyps and a subset of severe asthma. ${ }^{6}{ }^{10-12}$ An increase in airway neutrophils has been observed in subgroups of individuals with occupational or severe asthma, ${ }^{11} 1314$ smokers, ${ }^{15} 16$ elderly patients, ${ }^{17}$ in the presence of gastro-oesophageal reflux, ${ }^{18}$ following respiratory infections or endotoxin exposure, ${ }^{19}$ acute exacerbations ${ }^{20}$ and intense exercise $e^{21}$ or exposure to air pollution. ${ }^{22}$ However, as neutrophils are present in the sputum of normal subjects and in a number of respiratory conditions, the criteria to ascertain their role should ideally include an increase in the total number of cells, a high viability of the sample and the percentage of neutrophils compared with normal values.

In a recent study, $44 \%$ of patients were found to have the eosinophilic phenotype, $31 \%$ had the paucigranulocytic phenotype, and the neutrophilic or mixed granulocytic subtypes were each found in $13 \%{ }^{7}$ Subjects with purely eosinophilic asthma had the most pronounced AHR to mannitol, while the lowest degree of AHR was observed in subjects with neutrophilic asthma. In this issue of Thorax, Cowan et al expand our understanding of asthma inflammatory phenotypes by providing data on their prevalence (see page 384). ${ }^{23}$ The investigators not only found a lower prevalence of the neutrophilic phenotype in patients with asthma compared with that noted above and previously reported, ${ }^{67}$ but they also found that this pattern was absent after corticosteroid withdrawal in non-smoking patients who did not have respiratory infection. $^{23}$ Furthermore, this study confirms the influence of inhaled cortico- steroids on the pattern of airway inflammation, not only being associated with a decrease in eosinophils but also with an increase in sputum neutrophils.

Cowan et al report a high prevalence of sputum eosinophilia following corticosteroid withdrawal, $70 \%$ of patients experiencing a loss of control after being weaned off corticosteroids. This last observation suggests that these patients were in need of such medication because of an underlying active inflammatory process manifest by an increased number of airway eosinophils. This is also supported by the clinical improvement in asthma with fluticasone. In addition, this study confirms the excellent clinical response to corticosteroids in patients with the eosinophilic inflammatory phenotype. 524 Perhaps more importantly, as previously suggested, it shows that benefits could also be observed in patients without obvious airway eosinophilia. ${ }^{25} 26$

With respect to the determination of asthma phenotypes, it has become obvious that assessment of airway inflammatory patterns is influenced by the use of medications such as corticosteroids. It may be difficult to differentiate the true inflammatory cell phenotype from the effects of the current corticosteroid treatment, mechanisms related to the severity or type of asthma and environmental exposures. ${ }^{22} 27$ In the report by Cowan et $a l^{23}$ inhaled corticosteroid treatment with a high dose of fluticasone was associated with a significant increase in airway neutrophils, although only of about $10 \%$. However, there may be a dose effect with regard to this influence on sputum neutrophilia, and lower doses are likely to induce a smaller or no increase. There is also a possibility that patients with milder asthma not requiring corticosteroids or on a very low dose of inhaled corticosteroid could more frequently have a neutrophil phenotype, although this is probably to a large extent determined by environmental exposures, respiratory infections and age. In this regard, it is possible that the relatively unpolluted air in New Zealand is associated with lower numbers of airway neutrophils while in more polluted areas this phenotype could be more prevalent. As an example, a previous study examining the effects of short-term exposure to diesel traffic in people with asthma in a large city urban roadside environment showed an increase in biomarkers of neutrophilic inflammation, changes most consistently associated with exposure to ultrafine particles and elemental carbon. ${ }^{22}$
In the study by Cowan et al, as expected, forced expiratory volume in $1 \mathrm{~s}$ was the best predictor of increased airflow with treatment in both eosinophilic and non-eosinophilic asthma. The observation that the fraction of exhaled nitric oxide (FenO) can predict corticosteroid response in non-eosinophilic asthma is, however, surprising as FenO is considered to be a surrogate marker for airway eosinophilia. This may suggest that eosinophils are present in the airway wall or that other types of inflammatory airway processes responding to corticosteroids are reflected by FenO levels. ${ }^{28}$ Hence, FenO may be a better predictor of corticosteroid response than airway eosinophilia in this population.

With regard to the methods and choice of key measures used by Cowan et al, it is unlikely that the choice of cut-off points of $\geq 2 \%$ for eosinophils and $\geq 61 \%$ for neutrophils explains the results reported. These have been shown to discriminate adequately between these phenotypes, even taking into account possible environmental influences although, as already mentioned, there is a possible influence of environmental exposures on 'normal' values in a given area. ${ }^{6} 29-31$ It is also unlikely that the results would differ if whole sputum samples were analysed instead of selected plugs as the proportion of cells is similar. ${ }^{32}$ The absence of a placebo-controlled design could be considered a potential weakness of this study but such design, as mentioned by the authors, raises ethical issues in patients with asthma exacerbations, while the data obtained seem sufficiently robust to support the study conclusions. Finally, attraction, activation and survival of granulocytes in the airways are very dynamic processes and we should recognise that a single time-point sputum analysis provides a somewhat limited view of such a dynamic process.

In the report by Cowan et al, 31\% of patients had pauci-granulocytopenic asthma. $^{23}$ This pattern may be due to the presence of minimal or no airway inflammation at the time of measurement in patients with airway structural changes, possibly explaining the persistent changes in airway function. Porsbjerg et al reported that such patients had elevated levels of exhaled NO and AHR to mannitol, indicating increased disease activity compared with the neutrophilic group which had a low degree of AHR to mannitol and normal FenO levels. ${ }^{7}$ A possible benefit of corticosteroids in this group is supported by the findings of Cowan et al. 
Further research should be conducted on inflammatory asthma phenotypes and their clinical relevance. In this regard, treatments targeting granulocytes such as mepolizumab for eosinophils or those antagonising neutrophilic responses will contribute to an understanding of their role in the clinical expression of asthma and how best to treat these conditions. ${ }^{33}$

In conclusion, the report by Cowan and colleagues sheds more light on the prevalence of the various asthma phenotypes, particularly after corticosteroid withdrawal. The study shows that corticosteroids may increase neutrophil cell counts in induced sputum. It also suggests that, although baseline eosinophilia is a good predictor of the corticosteroid response, patients with no sputum eosinophilia may also show an improvement in their asthma with this treatment, particularly if they have increased Feno levels. Further research should be done on how these phenotypes evolve over time, particularly with regard to environmental exposures and medication use. Their influence on clinical outcomes and response to treatments should also be further examined. Phenotyping by the inflammatory cell type provides an opportunity to better target asthma therapy, ${ }^{34}$ but how to assess such phenotype should be done using rigorous methods and the effects of corticosteroid use, smoking and environmental exposures should be taken into account in the interpretation of these data.

Competing interests None.

Provenance and peer review Commissioned; not externally peer reviewed.

Thorax 2010;65:374-376

doi:10.1136/thx.2009.131391

\section{REFERENCES}

1. Holgate ST. Pathogenesis of asthma. Clin Exp Allergy 2008;38:872-97.

2. Boulet LP. Physiopathology of airway hyperresponsiveness. Curr Allergy Asthma Rep 2003:3:166-71

3. Boulet LP. Asymptomatic airway hyperresponsiveness: a curiosity or an opportunity to prevent asthma? Am J Respir Crit Care Med 2003;167:371-8.

4. Wenzel SE. Asthma: defining of the persistent adult phenotypes. Lancet 2006;368:804-13.

5. Pavord ID, Brightling CE, Woltmann G, et al. Noneosinophilic corticosteroid unresponsive asthma. Lancet 1999;353:2213-14.

6. Simpson JL, Scott R, Boyle M, et al. Inflammatory subtypes in asthma: assessment and identification using induced sputum. Respirology 2006; 11:54-61.

7. Porsbjerg C, Lund TK, Pedersen L, et al Inflammatory subtypes in asthma are related to airway hyperresponsiveness to mannitol and exhaled NO. J Asthma 2009;46:606-12.

8. Lovett CJ, Whitehead BF, Gibson PG. Asthma inflammatory phenotypes in kids. Eosinophilic airway inflammation and the prognosis of childhood asthma. Clin Exp Allergy 2007;37:1594-601.

9. Drews AC, Pizzichini MM, Pizzichini E, et al. Neutrophilic airway inflammation is a main feature of induced sputum in nonatopic asthmatic children. Allergy 2009;64:1597-601.

10. Ediger D, Sin BA, Heper A, et al. Airway inflammation in nasal polyposis: immunopathological aspects of relation to asthma. Clin Exp Allergy 2005;35:319-26.

11. Girard F, Chaboillez S, Cartier A, et al. An effective strategy for diagnosing occupational asthma: use of induced sputum. Am J Respir Crit Care Med 2004;170:845-50.

12. Wenzel SE, Schwartz LB, Langmack EL, et al. Evidence that severe asthma can be divided pathologically into two inflammatory subtypes with distinct physiologic and clinical characteristics. Am J Respir Crit Care Med 1999; 160:1001-8.

13. Anees W, Huggins V, Pavord ID, et al. Occupational asthma due to low molecular weight agents: eosinophilic and non-eosinophilic variants. Thorax 2002; 57:231-6.

14. Jatakanon A, Uasuf C, Maziak W, et al. Neutrophilic inflammation in severe persistent asthma. $A m ~ J$ Respir Crit Care Med 1999;160:1532-9.

15. Boulet LP, Lemière C, Archambault F, et al. Smoking and asthma: clinical and radiologic features, lung function, and airway inflammation. Chest 2006;129:661-8.

16. Chalmers GW, MacLeod KJ, Thomson L, et al. Smoking and airway inflammation in patients with mild asthma. Chest 2001;120:1917-22.

17. Thomas RA, Green RH, Brightling CE, et al. The influence of age on induced sputum differential cell counts in normal subjects. Chest 2004;126:1811-14.

18. Carpagnano GE, Resta O, Ventura MT, et al. Airway inflammation in subjects with gastro-oesophageal reflux and gastro-oesophageal reflux-related asthma. J Intern Med 2006;259:323-31.

19. Pallan S, Mahony JB, O'Byrne PM, et al. Asthma management by monitoring sputum neutrophil count. Chest 2008;134:628-30.
20. Fahy JV, Kim KW, Liu J, et al. Prominent neutrophilic inflammation in sputum from subjects with asthma exacerbation. J Allergy Clin Immunol 1995;95:843-52.

21. Bougault V, Turmel J, St-Laurent J, et al. Asthma, airway inflammation and epithelial damage in swimmers and cold-air athletes. Eur Respir $J$ 2009:33:740-6.

22. McCreanor J, Cullinan P, Nieuwenhuijsen MJ, et al. Respiratory effects of exposure to diesel traffic in persons with asthma. $N$ Engl J Med 2007:357:2348-58.

23. Cowan DC, Cowan J0, Palmay R, et al. Effects of steroid therapy on inflammatory cell subtypes in asthma. Thorax 2010;65:384-90.

24. Pizzichini MM. Is sputum eosinophilia a good or poor predictor of benefit from inhaled corticosteroid therapy in asthma? Eur Respir J 2002; 20:1359-61.

25. Godon P, Boulet LP, Malo JL, et al. Assessment and evaluation of symptomatic steroid-naive asthmatics without sputum eosinophilia and their response to inhaled corticosteroids. Eur Respir $J$ 2002;20:1364-9.

26. Lex C, Jenkins G, Wilson NM, et al. Does sputum eosinophilia predict the response to systemic corticosteroids in children with difficult asthma? Pediatr Pulmonol 2007;42:298-303.

27. Wenzel SE, Szefler SJ, Leung DY, et al. Bronchoscopic evaluation of severe asthma. Persistent inflammation associated with high dose glucocorticoids. Am J Respir Crit Care Med 1997:156:737-43.

28. Smith AD, Cowan J0, Brassett KP, et al. Exhaled nitric oxide: a predictor of steroid response. Am J Respir Crit Care Med 2005;172:453-9.

29. Kips JC, Inman MD, Jayaram L, et al. The use of induced sputum in clinical trials. Eur Respir J Suppl 2002;37:47-50s.

30. Belda J, Leigh R, Parameswaran K, et al. Induced sputum cell counts in healthy adults. Am J Respir Crit Care Med 2000;161:475-8.

31. Spanevello A, Confalonieri M, Sulotto F, et al Induced sputum cellularity. Reference values and distribution in normal volunteers. Am J Respir Crit Care Med 2000;162:1172-4

32. Pizzichini E, Pizzichini MM, Efthimiadis A, et al. Measurement of inflammatory indices in induced sputum: effects of selection of sputum to minimize salivary contamination. Eur Respir J 1996;9:1174-80.

33. Yamagata T, Ichinose M. Agents against cytokine synthesis or receptors. Eur J Pharmacol 2006;533:289-301.

34. Reddel HK, Taylor DR, Bateman ED, et al. An official American Thoracic Society/European Respiratory Society statement: asthma control and exacerbations: standardizing endpoints for clinical asthma trials and clinical practice. $A m \mathrm{~J}$ Respir Crit Care Med 2009; 180:59-99. 